This is the final peer-reviewed accepted manuscript of:

Lugli F, Weber M, Giovanardi T, Arrighi S, Bortolini E, Figus C, Marciani G, Oxilia G, Romandini M, Silvestrini S, Jochum KP, Benazzi S, Cipriani A (2020) Fast offline data reduction of laser ablation MC-ICP-MS Sr isotope measurements via the interactive Excel-based spreadsheet 'SrDR'. Journal of Analytical Atomic Spectrometry 35, 852 862.

The final published version is available online at:

https://doi.org/10.1039/C9JA00424F

Rights / License:

The terms and conditions for the reuse of this version of the manuscript are specified in the publishing policy. For all terms of use and more information see the publisher's website.

This item was downloaded from IRIS Università di Bologna (https://cris.unibo.it/)

When citing, please refer to the published version. 


\title{
Fast offline data reduction of laser ablation MC-ICP-MS Sr isotope measurements via the interactive Excel-based spreadsheet 'SrDR'
}

\author{
Federico Luglia,b,*, Michael Weber, ${ }^{c,}$, Tommaso Giovanardi ${ }^{a}, *$, Simona Arrighi ${ }^{b}$, Eugenio Bortolini ${ }^{b}$, Carla Figus $^{b}$,

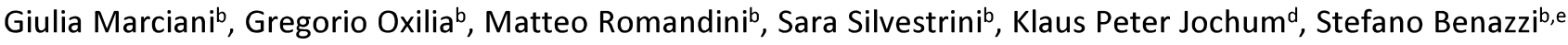 \\ \& Anna Cipriania,f
}

aDepartment of Chemical and Geological Sciences, University of Modena and Reggio Emilia, Via Campi 103, 41125 - Modena, Italy

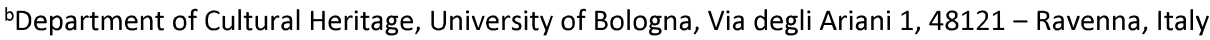

'Institute of Geosciences, Johannes Gutenberg-University Mainz, Johann-Joachim-Becher-Weg 21, 55128, Mainz, Germany

${ }^{d}$ Climate Geochemistry Department, Max Planck Institute for Chemistry (Otto-Hahn-Institute), Postbox 3060, 55020, Mainz, Germany

eDepartment of Human Evolution, Max Planck Institute for Evolutionary Anthropology, Leipzig, Germany

fLamont-Doherty Earth Observatory, Columbia University, Palisades, New York, USA

*corresponding authors: federico.lugli6@unibo.it; tommaso.giovanardi@gmail.com

\begin{abstract}
Strontium isotopes are applied to a wide range of scientific fields and to different types of sample materials, providing valuable information foremost about provenance and age, but also on diagenetic processes and mixing relationships between different $\mathrm{Sr}$ reservoirs. The development of in-situ analytical techniques, such as laser ablation ICP-MS, has improved our understanding of Sr isotope variability in several field of application, because of the possibility to discriminate small-scale changes and their spatial distribution. However, large outputs of Sr isotope data are produced by laser ablation MC-ICP-MS systems, which necessitate of multiple offline steps to correct and assess the data. This requires the availability of simple and user-friendly tools,
\end{abstract}


easily manageable also by non-specialists. With this in mind, we developed SrDR, an Excel-based interactive data reduction spreadsheet ('SrDR', Sr-Data-Reduction) for the processing of Sr isotopes measured by LA-MCICP-MS. The SrDR spreadsheet is easily customizable (a) to meet user-specific analytical protocols, (b) for different instruments (i.e. Nu Plasma vs. Neptune), and (c) for diverse target materials (e.g. Rare Earth Elements enriched or depleted samples). We include also several examples relevant to low and high temperature geochemistry fields - a fossil tooth, a modern seashell, a speleothem sample and plagioclase crystals - to show how different sample materials are corrected for different interfering masses.

Significance to JAAS: In-situ strontium isotope analyses are pivotal in several scientific fields; however, off-line data reduction can be complex and time-consuming. Here, we propose an interactive Excel-tool for the fast correction of Sr isotope measurements by LA-MC-ICP-MS.

\section{Introduction}

Strontium isotopes are one of the most versatile isotopic systematics due to the relatively high concentration of $\mathrm{Sr}$ in nature and its ubiquitous presence in geological and biological materials [1]. The $\mathrm{Sr}$ isotopic composition in a sample or reservoir changes continuously with time because of the radioactive decay of the parent ${ }^{87} \mathrm{Rb}$ to ${ }^{87} \mathrm{Sr}$. Therefore, the ${ }^{87} \mathrm{Sr} /{ }^{86} \mathrm{Sr}$ ratio in a target material depends on the time elapsed since the closure of the system and the initial $\mathrm{Rb} / \mathrm{Sr}$ ratio of the reservoir. The very first measurements of $\mathrm{Sr}$ isotopes have found application in geochronological and petrological studies of terrestrial and extraterrestrial rocks to determine their age and differentiation history [ 1 and references therein]. Nowadays $\mathrm{Sr}$ isotopes are applied with great success to a plethora of scientific fields, such as archaeology, anthropology, ecology, paleoclimatology and forensic sciences [e.g. 2-32]. In particular, ${ }^{87} \mathrm{Sr} /{ }^{86} \mathrm{Sr}$ ratios measured in tooth enamel have played a crucial role in understanding mobility patterns of ancient humans and animals [see 9 for a complete 
review; 18,28$)$, but also to trace several other unconventional evidences such as, e.g., water residence time and aeolian contribution in speleothem formation [33] or diagenetic processes affecting ancient fossil bones [34].

The presence of $\mathrm{Sr}$ in the low temperature realm is related to erosional and weathering processes of the crystalline bedrock where $\mathrm{Sr}$ ions enter the local ecosystem through soil and water [9]. Natural low temperature archives of $\mathrm{Sr}$, suitable proxies of paleoclimate and/or landscape changes, include, among others, bioapatites (i.e. bones and teeth) and calcium carbonates (e.g. speleothems and seashells), where $\mathrm{Sr}^{2+}$ ions substitute $\mathrm{Ca}$ in their crystal lattice [9]. As a result, the ${ }^{87} \mathrm{Sr} /{ }^{86} \mathrm{Sr}$ ratios in biological tissues reflect the $\mathrm{Sr}$ isotope composition of the local available Sr [9]. The Sr of speleothems instead derives from cave drip water, which contains a mixture of the $\mathrm{Sr}$ from the soil above the cave, including potential external sources, and the carbonate host rock [33].

Sr isotopes are traditionally analysed by Thermal Ionization Mass Spectrometry after separation of Sr from the matrix by standard ion-exchange chromatographic techniques. However, more recently, laser ablation multi collector inductively coupled plasma mass spectrometry (MC-ICP-MS) systems have been widely employed to measure Sr isotopes in-situ in e.g. fossil teeth [13,29], speleothems [39], fish otolith [40] and mineral phases [41]. The intrinsic features of the LA-MC-ICP-MS methodology allow rapid analyses and generating large amounts of time-resolved data per analytical session in high spatial resolution bypassing laborious chemical work. Hence, to correct for matrix interferences and instrumental biases arising during LA analyses and to manage the large amount of data, a robust and reproducible method for offline data reduction and handling is highly desirable.

To date, several data reduction software to correct LA-MC-ICP-MS analyses is already accessible [42-45]. Nevertheless, adapting this software to meet the measurement criteria of each user requires advanced programming skills due to limited customizable settings in the current available versions. 
In this study, we propose an Excel-based easily accessible and interactive data reduction spreadsheet ('SrDR', Sr-Data-Reduction), for fast correction of Sr isotope measurements by LA-MC-ICP-MS. Given that different instruments (i.e. Nu Plasma vs. Neptune) and different data acquisition protocols (e.g. measurement of $\mathrm{m} / \mathrm{z}$ 83.5 and 86.5 or not) may require customization of the spreadsheet itself, we present several versions of the same protocol, based on analytical methods published in the literature, to meet the needs of a comprehensive group of users. The spreadsheet is easy to self-customize, and being an Excel-written code maintains its interactive features. With this sheet, the user is able to import all raw data files contained in a specific folder, to interactively select the background and the analyses cycles, to correct for the main Sr interferences ( $\mathrm{Kr}, \mathrm{Rb}$, REE, Ca dimers and argides; Table 1) and instrumental biases and to automatically transfer the results in a final table. We also present and discuss several applications of the SrDR protocol for different materials such as teeth, shells, speleothems and mineral phases to illustrate how the spreadsheet works.

\section{Data reduction philosophy}

The extensive exploitation and the concurrent analytical advancement of isotope measurements with the output of extensive datasets have led to the development of software for fast data processing and correction of specific dataset and isotope systematics [e.g. 35-38]. Different procedures for data reduction of in-situ Sr isotope analyses are also currently present in the literature [46]. However, while there is a shared agreement on the fundamental corrections (as $\mathrm{Kr}, \mathrm{Rb}$ and mass bias), several other adjustments applicable to the data are debated and applied depending on research group preferences. For this reason, we present several versions of the same spreadsheet with different data reduction procedures (as reported in Table 2) so that readers are able to choose the preferred version based on the mass spectrometer employed for data acquisition, masses collected during the analytical session and sample typology. 
All spreadsheets include a Visual Basic macro for the import of raw data, a macro for the deletion of raw data (if needed) and a macro for fast copy \& paste of the final results corrected for interferences and mass bias (Fig. 1). The workflow of the spreadsheet is summarized in Fig. 1 and discussed step by step in the following sections. Regardless of the data reduction protocol, we note here that each spreadsheet evidently yields different ${ }^{87} \mathrm{Sr} /{ }^{86} \mathrm{Sr}$ ratios, which result from the application of different processing steps (e.g. the ${ }^{87} \mathrm{Sr} /{ }^{86} \mathrm{Sr}$ ratio corrected for the sole $\mathrm{Rb}$ and mass bias vs. the ${ }^{87} \mathrm{Sr} /{ }^{86} \mathrm{Sr}$ ratio additionally corrected for the REEs and Ca dimers and argides).

\section{Data reduction steps}

\subsection{Raw data import}

Raw data can be manually copied into the spreadsheet (starting from cell 'O67') or automatically imported using the button 'Import raw data' within the Data sheet (Fig. 1). This macro imports all the raw data files included in the same folder of the SrDR file, generating a new sheet for each analysis and renaming it according to the file name. We suggest, prior to import the whole dataset, to check if the raw data template fits the SrDR length. If not, the user can add or remove lines to match the length. It is preferable that the first row of data coincides with the first data reduction row at row number 67 . Although this operation is not strictly necessary, if the data start much lower, the spreadsheet can develop issues with graph visualization and data/background selection. The ${ }^{84} \mathrm{Sr}$ signal graph within the spreadsheet is conceived to help the user identify whether or not the copied data fit within the basic SrDR format, by visually checking if the analysis of the sample is plotted together with the preceding background. To overcome any issue, the user can also simply delete the excess calculation rows or add new ones, being careful to avoid cell miss-referencing. Any modification applied to the SrDR 'Data' spreadsheet is preserved when new data are imported 'Import raw data'. We also suggest exporting the raw data from the mass spectrometer without any alphabetic or numeric string at the end of the 
data columns (i.e. the last row of the raw data sheet should be the last cycle of analysis). The presence of extra strings could clash with the proper visualization of signals and graphs. To avoid this issue altogether, the user can manually delete the last few rows in the raw data file prior to import.

\subsection{Krypton correction as background subtraction}

Given the presence of $\mathrm{Kr}$ on $\mathrm{m} / \mathrm{z} 84$ and 86 , the interferences on these masses need to be properly assessed and corrected. The main sources of $\mathrm{Kr}$ in the LA-MC-ICP-MS system are the Ar and He used to generate the plasma and to carry the sample within the mass spectrometer [46]. The most common method to correct for the $\mathrm{Kr}$ presence is the so called 'on peak zero' method. This method requires the measurement of the gas background (generally acquired at the beginning of each analysis during laser warm-up) and the subsequent subtraction of the background signals from those recorded during analysis. This method also corrects for the potential minor presence of $\mathrm{Sr}$ and $\mathrm{Rb}$ impurities on the other masses.

Our spreadsheet exploits the 'on peak zero' method to correct for $\mathrm{Kr}$, subtracting the average background signal from each single analysis cycle. The background selection is easy to perform thanks to the OFFSET Excel function. Within the 'Data selection' box the user writes the background start cycle of choice and the number of background cycles to use for the average calculation. This process is interactive: after this first operation, the user can try other background parameters by clicking the arrows up or down or by re-typing the parameters, while examining the graphs (e.g. ${ }^{88} \mathrm{Sr}$ and ${ }^{84} \mathrm{Sr}$ signals) and the final output (Fig. 1).

\subsection{Analysis selection}

The number of analytical cycles to be included in the calculations are selected within the 'Data selection' box. Similarly to the background selection, the data can be interactively selected using the small arrows or by typing 
the data interval. While looking at the ${ }^{87} \mathrm{Sr} /{ }^{86} \mathrm{Sr}$ profile graph, the user can choose different portions of the analysis (e.g. in the case of a laser ablation raster with variable isotopic domains) saving the average value for each sub-profile.

\subsection{Rare Earth Element correction}

Rare Earth Elements (REEs) can be abundant for example in fossil carbonate samples (in the order of tens or even hundreds of $\mu \mathrm{g} / \mathrm{g}$ ) and generally scarce in modern specimens ( $\sum \mathrm{REE}<\mathrm{ca} .10 \mu \mathrm{g} / \mathrm{g}$ ). Doubly charged ions of $\mathrm{Yb}$ and Er interfere with all the masses of interests, potentially biasing both the ${ }^{87} \mathrm{Sr} /{ }^{86} \mathrm{Sr}$ and the ${ }^{84} \mathrm{Sr} /{ }^{86} \mathrm{Sr}$ ratios. In particular, ${ }^{176} \mathrm{Yb}^{2+}$ interferes with mass $88,{ }^{174} \mathrm{Yb}^{2+}$ with mass $87,{ }^{172} \mathrm{Yb}^{2+}$ with mass $86,{ }^{170} \mathrm{Yb}^{2+}$ and ${ }^{170} \mathrm{Er}^{2+}$ with mass 85 and ${ }^{168} \mathrm{Yb}^{2+}$ and ${ }^{168} \mathrm{Er}^{2+}$ with mass 84 . Moreover, ${ }^{166} \mathrm{Er}^{2+}$ and ${ }^{164} \mathrm{Er}^{2+}$ are present on masses 83 and 82 , respectively. Mass 82 is also interfered by ${ }^{164} \mathrm{Dy}^{2+}$. One of the most applied method to correct for these elements is the so called 'peak stripping' [46]. Doubly charged ions are measured on half-masses (as 86.5 for ${ }^{174} \mathrm{Yb}^{2+}$ and 83.5 for ${ }^{167} \mathrm{Er}^{2+}$ ), and subtracted from $\mathrm{Kr}$, $\mathrm{Sr}$ and $\mathrm{Rb}$ masses using natural isotope ratios. For example: ${ }^{174} \mathrm{Yb}^{2+}$ is calculated by multiplying the signal on mass $86.5\left({ }^{173} \mathrm{Yb}^{2+}\right)$ by the ratio of ${ }^{174} \mathrm{Yb}(32.025 \%)$ and ${ }^{173} \mathrm{Yb}$ (16.103\%) natural abundances. Other methods check and correct for the presence of Er using mass 83, after background subtraction and Ca dimers and argides correction [47] (see next paragraph).

\subsection{Ca dimers and argides correction}

Several authors [48] have observed that ArCa and CaCa molecules (see ESI Tables 1 - 3) interfere with $\mathrm{Sr}$ masses when high $\mathrm{Ca} / \mathrm{Sr}$ material is analysed. In our experience, Ca dimers and argides may affect the accuracy of the ${ }^{87} \mathrm{Sr} /{ }^{86} \mathrm{Sr}$ ratio, but only within in-run analytical error, as also observed by others [43, 49]. These molecules are commonly monitored on $\mathrm{m} / \mathrm{z} 82\left({ }^{40} \mathrm{Ca}^{42} \mathrm{Ca}\right.$ and $\left.{ }^{40} \mathrm{Ar}{ }^{42} \mathrm{Ca}\right)$ after background subtraction. However, 
if the sample contains high REE levels, most of the $\mathrm{m} / \mathrm{z} 82$ signal may derive from the presence of ${ }^{164} \mathrm{Dy}^{2+}$. Only few studies have considered this issue [11,50-52]: e.g. Horstwood et al. [11] corrected for this interference by employing a three-sequence peak jumping routine and acquiring, among others, mass $81.5\left({ }^{163} \mathrm{Dy}{ }^{2+}\right)$ to correct for mass 82 by peak stripping. However, this procedure is difficult/time-consuming given that it requires peak jumping mode or the exclusion of other masses (e.g. 83.5) from the analysis. Our correction protocol omits mass 81.5. Thus, in case of high-REE samples, we suggest to bypass the Ca dimers and argides correction, focusing on the sole REE correction. Later in this paper, we will show how mass 82 is strongly affected by high concentration of Dy in a Middle Pleistocene fossil tooth. Otherwise, if the REE concentration in the sample is low (e.g. in modern shell specimens), the ArCa and CaCa correction can be performed using the Dy-uncorrected mass 82 and ignoring the Dy interference.

Our spreadsheets (V1 and V2 spreadsheets of both Nu and Neptune, and V3 spreadsheet of Nu; see Table 2) correct for ArCa and CaCa molecules following the protocol presented in Weber et al. [39] for speleothem analyses and here briefly exemplified for mass 86 :

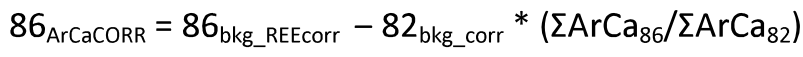

where $86_{\text {ArCaCORR }}$ is the corrected signal on mass $86 ;=86_{\text {bkg_REEcorr }}$ is the signal on mass 86 corrected for background and REE; $82_{\text {bkg_corr }_{-}}$is the signal on mass 82 corrected for the background. $\sum \mathrm{ArCa}_{86}$ is the sum of the relative portion of $\mathrm{Ca}$ argides on mass 86 and $\sum \mathrm{ArCa}_{82}$ is the sum of the relative portion of $\mathrm{Ca}$ argides on mass 82 , based on their natural occurrence [53]. The same procedure is also performed to correct for the Ca dimers interference.

3.6. Mass bias and $\mathrm{Rb}$ corrections 
The two main sources of inaccuracy of the ${ }^{87} \mathrm{Sr} /{ }^{86} \mathrm{Sr}$ ratio are the mass bias and $\mathrm{Rb}$ content. While the former mostly derives from the instrumental discrimination of heavier vs. lighter masses (mass-dependent fractionation), the latter is related to the matrix composition of the sample. To obtain the interference-free ${ }^{87} \mathrm{Sr}$, the isobar ${ }^{87} \mathrm{Rb}$ needs to be calculated starting from the signal of ${ }^{85} \mathrm{Rb}$ using the natural ${ }^{87} \mathrm{Rb} /{ }^{85} \mathrm{Rb}$ ratio equal to 0.38567 . Mass bias discrimination on the ${ }^{87} \mathrm{Rb} /{ }^{85} \mathrm{Rb}$ ratio is calculated using an exponential law, assuming that instrument mass discrimination is the same for both $\mathrm{Rb}$ and $\mathrm{Sr}$, and normalizing to an ${ }^{88} \mathrm{Sr} /{ }^{86} \mathrm{Sr}$ ratio of 8.3752 . After ${ }^{87} \mathrm{Rb}$ signal is subtracted from mass 87 , the ${ }^{87} \mathrm{Sr} /{ }^{86} \mathrm{Sr}$ ratio is corrected for mass bias as done for the $\mathrm{Rb}$. The following equations summarize how the mass bias correction is done through the exponential law [as described in 44]:

$$
\begin{gathered}
\beta=\frac{\ln \left(\frac{{ }_{n r} R_{u v}^{\text {true }} R_{u v}^{\text {meas }}}{M_{u}}\right.}{\ln \left(\frac{u}{M_{v}}\right)} \\
R_{i j}^{\text {corr }}=R_{i j}^{\text {meas }} \times\left(\frac{M_{i}}{M_{j}}\right)
\end{gathered}
$$

where $\beta$ is the mass bias factor; ${ }_{n r} R_{u v}^{\text {meas }}$ and ${ }_{n r} R_{u v}^{\text {true }}$ are the measured and reference 'true' ratios of the chosen normalizing ratio $(n r) ; M_{u}$ and $M_{v}$ are the atomic masses of the normalizing ratio isotopes; $R_{i j}^{\text {meas }}$ and $R_{i j}^{\text {corr }}$ are the measured and corrected isotopic ratios (e.g. ${ }^{87} \mathrm{Sr} /{ }^{86} \mathrm{Sr}$ ); $M_{i}$ and $M_{j}$ are the atomic masses of the two isotopes considered for the ratio. At the end of all the mathematical corrections, the ${ }^{87} \mathrm{Sr} /{ }^{86} \mathrm{Sr}$ outliers are $2 \sigma-$ filtered.

\section{7. ${ }^{89} \mathrm{Y}$ monitoring}

Some analytical protocols presented in literature [48] use $\mathrm{m} / \mathrm{z} 89(\mathrm{Y})$ as a proxy for the REE content of the sample. This mass, adjacent to mass 88 , can be easily collected with both Neptune and Nu Plasma instruments. 
Although we believe that most of the inferences on mass 89 can be easily deduced using other masses (e.g. 82 , 83 or half-masses; see paragraph 5.1.), we present here some protocols where mass 89 is collected (V1 spreadsheet of both Nu and Neptune, see Table 2). In the Neptune V1 spreadsheet, the user can input or not mass 89 without interfering with the calculation (mass 89 is the last column of the dataset, so it can be easily left empty). In the Nu V1 spreadsheet, it is mandatory to have the first column of the dataset dedicated to ${ }^{89} \mathrm{Y}$ (or at least an empty column before the actual dataset). If the Nu user did not collect ${ }^{89} \mathrm{Y}$, the $\mathrm{V} 2$ spreadsheet might be used (Table 2).

\section{Spreadsheet outcome and specifications}

All spreadsheets provide the ${ }^{87} \mathrm{Sr} /{ }^{86} \mathrm{Sr}$ ratio corrected for the sole background, $\mathrm{Rb}$ and mass bias (without REE and $\mathrm{Ca}$ dimers/argides and named 'Unc.' within the sheet); in addition, the different versions of the spreadsheet may yield additional ${ }^{87} \mathrm{Sr} /{ }^{86} \mathrm{Sr}$ values, based on the type of correction applied (e.g. REE only or both REE and Ca dimers/argides). Other parameters reported in the spreadsheet are the 2-standard error (2se) of the mean, the number of unfiltered-cycles considered for the analysis $(n)$, the total $\mathrm{Sr}$ signal $(\mathrm{V})$, the ${ }^{84} \mathrm{Sr} /{ }^{86} \mathrm{Sr}$ ratio, the ${ }^{85} \mathrm{Rb} /{ }^{88} \mathrm{Sr}$ ratio and the average signal collected for each mass. These values can be automatically copied in the 'Results' sheet using the corresponding export buttons ('Copy \& Paste'), located below the resultcolumn of interest.

The spreadsheets are compatible with Excel 2007 and newer versions, but also with LibreOffice and OpenOffice. Please note that to use the macros, the spreadsheet must be saved as an Excel Macro-Enabled Workbook.

\section{Applications}




\subsection{Fossil tooth}

The ${ }^{87} \mathrm{Sr} /{ }^{86} \mathrm{Sr}$ ratio of calcium phosphates is relatively challenging to measure by LA-MC-ICP-MS, because of the formation of molecules with $\mathrm{m} / \mathrm{z} 87$, namely ${ }^{40} \mathrm{Ar}^{31} \mathrm{p}^{16} \mathrm{O}$ and ${ }^{40} \mathrm{Ca}^{31} \mathrm{p}^{16} \mathrm{O}$, during analysis. The interference of these molecules has been observed by many authors $[11,28,54,55]$, and yields higher ${ }^{87} \mathrm{Sr} /{ }^{86} \mathrm{Sr}$ ratios than expected, in particular for samples with relatively low $\mathrm{Sr}$ concentration $(<<1000 \mu \mathrm{g} / \mathrm{g})$. The two main methods to correct for the influence of these molecules are the following: 1) using $\mathrm{N}_{2}$ to reduce oxide levels within the plasma [56]; 2) calibrate the daily formation of CaPO and ArPO through the analysis of a set of matrix-matched reference materials $[11,28]$. In this paper, we correct for the presence of these interferences (Ar-CaPO) using the protocol described in Horstwood et al. [11] and Lugli et al. [28], namely a calibration curve with in-house reference materials (i.e. teeth). This calibration is performed by analyzing a shark tooth ([Sr] ca. $1000 \mu \mathrm{g} / \mathrm{g}$ ), a bovine tooth ([Sr] ca. $350 \mu \mathrm{g} / \mathrm{g}$ ) and a swine tooth ([Sr] ca. $200 \mu \mathrm{g} / \mathrm{g}$ ) [28]. A daily curve is built with the ${ }^{88} \mathrm{Sr}$ signals (as a proxy of the $\mathrm{Sr}$ content) and the accuracy of the Ar-CaPO uncorrected ${ }^{87} \mathrm{Sr} /{ }^{86} \mathrm{Sr}$ ratios (i.e. LA data are normalized to the 'true' solution MC-ICP-MS results). Then, the resulting equation is employed to mathematically correct the unknown bioapatite data.

Additionally, in this paragraph, we show how the strong presence of REEs within a fossil sample may also considerably bias the final ${ }^{87} \mathrm{Sr} /{ }^{86} \mathrm{Sr}$ ratio.

We analysed the enamel ${ }^{87} \mathrm{Sr} /{ }^{86} \mathrm{Sr}$ ratio of a Middle Pleistocene (ca. 600ka) rhinoceros tooth (sample ID: RHIS14; stored at University of Modena and Reggio Emilia) using a $213 \mathrm{~nm}$ laser ablation system (New Wave UP) and a Neptune MC-ICP-MS (Thermo Scientific), both housed at the Centro Interdipartimentale Grandi Strumenti (CIGS) of the University of Modena and Reggio Emilia. We employed linear raster of $100 \mu \mathrm{m} \times 750$ $\mu \mathrm{m}$, a fluence of $\sim 12 \mathrm{~J} / \mathrm{cm}^{2}$, a frequency of $10 \mathrm{~Hz}$ and a scan speed of $5 \mu \mathrm{m} / \mathrm{s}$. A He flux of ca. $0.6 \mathrm{~L} / \mathrm{min}$ was used to carry the sample into the mass spec. No additional gases, besides the Ar, were employed (e.g. $\mathrm{N}_{2}$ ). During the session, the modern swine tooth was also measured several times as unknown. Its ${ }^{87} \mathrm{Sr} /{ }^{86} \mathrm{Sr}$ ratio 
was previously determined by solution MC-ICP-MS and resulted equal to $0.70899 \pm 0.00001$ (2se) [28]. The swine tooth, measured by LA-MC-ICP-MS, yielded an Ar-CaPO uncorrected ${ }^{87} \mathrm{Sr} /{ }^{86} \mathrm{Sr}$ ratio of $0.70992 \pm 0.00043$ $(2 \sigma, n=16)$. After the Ar-CaPO calibration, the ${ }^{87} \mathrm{Sr} /{ }^{86} \mathrm{Sr}$ ratio dropped to $0.70891 \pm 0.00031(2 \sigma, n=16)$. REE corrected and uncorrected values were identical within the error. This specimen shows in fact very low REE concentrations ( $($ REE $<1 \mu \mathrm{g} / \mathrm{g})$.

The fossil rhinoceros tooth ([Sr] ca. $400 \mu \mathrm{g} / \mathrm{g}$ ) shows very distinct isotopic values whether the REE correction is applied or not (Fig. 2). Step-by-step results are shown in Figure 3. The REE uncorrected ${ }^{87} \mathrm{Sr} /{ }^{86} \mathrm{Sr}$ ratio is 0.71036 \pm 0.00005 ( 2 se), while the REE corrected ratio is $0.70966 \pm 0.00005$. After the CaPO daily calibration, these two values become 0.71008 and 0.70937 respectively. Considering that the bulk Sr isotope ratios, measured by dissolution MC-ICP-MS, is equal to 0.70954 for enamel and to 0.70933 for dentine, the LA data seem more accurate after the REE correction is applied. The REE uncorrected ${ }^{84} \mathrm{Sr} /{ }^{86} \mathrm{Sr}$ ratio is $0.06031 \pm 0.00011$, while the REE corrected ratio is $0.05556 \pm 0.0004$. In this case, the ${ }^{84} \mathrm{Sr} /{ }^{86} \mathrm{Sr}$ is overly high before the correction, but seems overcorrected after the REE peak-stripping correction, similarly to what has been observed by other authors $[9,47]$. Moreover, compared to modern samples, this specimen shows quite high signals for all the masses, likely related to the presence of REEs $(\mathrm{m} / \mathrm{z} 82=3.4 \mathrm{E}-03 \mathrm{~V} ; \mathrm{m} / \mathrm{z} 83=1.4 \mathrm{E}-03 \mathrm{~V} ; \mathrm{m} / \mathrm{z} 85.5=2.2 \mathrm{E}-04 \mathrm{~V}$; $\mathrm{m} / \mathrm{z} 86.5=3.0 \mathrm{E}-04 \mathrm{~V}$; Fig. 2). The signal of mass 82 is correlated with the signal of mass $86.5\left({ }^{173} \mathrm{Yb} \mathrm{b}^{2+}\right.$ as proxy of REE content; $\left.r^{2}=0.33\right)$, but it is not with the signal of mass $88\left({ }^{88} \mathrm{Sr}\right.$ as proxy of the ablation behavior of the sample; $\left.r^{2}=0.004\right)$. Thus, we suggest that the signal recorded on $m / z 82$ (Dy + ArCa and CaCa) reflects the presence of Dy, rather than the formation of $\mathrm{ArCa}$ and $\mathrm{CaCa}$ during the ablation of the specimen.

\subsection{Modern seashell}

We measured the Sr isotope composition of a modern seashell (sample ID: SS12; stored at the University of Modena and Reggio Emilia), collected from the Italian seashore, using the same instrumentation presented in 
section 5.1. We thus employed the same parameters of the rhinoceros' tooth analysis, but using spots of 100 $\mu \mathrm{m}$ in diameter ( $40 \mathrm{~s}$ of dwell time) instead of lines. Given that this sample is a modern calcium carbonate shell with low REE content, we did not employ any further correction (i.e. REE, Ca dimers/argides or Ca-ArPO calibration). Raw data files of 10 different ablation lines were automatically imported using the 'Import raw data' macro into the Neptune V3 Sr-DR worksheet. On average, the seashell yields an ${ }^{87} \mathrm{Sr} /{ }^{86} \mathrm{Sr}$ ratio of 0.70917 $\pm 0.00003(2 \sigma, \mathrm{n}=10)$, perfectly matching the modern seawater composition [57], and an ${ }^{84} \mathrm{Sr} /{ }^{86} \mathrm{Sr}$ ratio of $0.05650 \pm 0.00010(2 \sigma, n=10)$, in line with the expected natural ratio. Although few analyses present a slightly deviated ${ }^{84} \mathrm{Sr} /{ }^{86} \mathrm{Sr}$ ratio (see e.g. analysis \#6 in Fig. 4), their ${ }^{87} \mathrm{Sr} /{ }^{86} \mathrm{Sr}$ ratio is still accurate. We note here that the entire processing of the data including data import, selection and export did not require more than 10 minutes.

\subsection{Speleothem}

A stalagmite sample from the Hüttenbläserschachthöhle (Germany) $[58,59]$ has been analysed at the Max Planck Institute for Chemistry, Mainz, following methods described in Weber et al. [39]. The sample mainly consists of aragonite and is therefore highly suited for in-situ LA-MC-ICP-MS analyses of Sr-isotopes due to the high Sr concentration in aragonite compared to calcite. Three sections of the stalagmite (samples ID: HBSH-1-9, HBSH-1-11 and HBSH-1-20) have each been analysed with three line scans of $750 \mu \mathrm{m}$ positioned directly next to each other within a single growth layer (see Fig. 5). The ${ }^{87} \mathrm{Sr} /{ }^{86} \mathrm{Sr}$ ratio was determined using a New Wave UP $213 \mathrm{~nm}$ laser ablation system coupled to a Nu Plasma MC-ICP-MS. Each line scan was performed using a circular spot size of $100 \mu \mathrm{m}$, a scan speed of $5 \mu \mathrm{m} / \mathrm{s}$, a frequency of $10 \mathrm{~Hz}$ and a fluence of $12-14 \mathrm{~J} / \mathrm{cm}^{2}$. The stalagmite sections are store at the Institute of Geosciences, Mainz.

Correction of $\mathrm{Ca}$ argides and dimers does not significantly affect the resulting ${ }^{87} \mathrm{Sr} /{ }^{86} \mathrm{Sr}$ ratios, unlike the REE correction. Stalagmite slab HBSH-1-20 yielded a REE uncorrected average ${ }^{87} \mathrm{Sr} /{ }^{86} \mathrm{Sr}$ ratio of $0.70961 \pm 0.00003$ $(2 \sigma, n=3)$. Nevertheless, after REE and Ca argide and dimer correction, the ${ }^{87} \mathrm{Sr} /{ }^{86} \mathrm{Sr}$ ratio decreased to an 
average ratio of $0.70953 \pm 0.00003(2 \sigma, n=3)$ and a ${ }^{84} \mathrm{Sr} /{ }^{86} \mathrm{Sr}$ ratio of $0.05621 \pm 0.00003(2 \sigma, n=3)$. The same is true for the two other stalagmite slabs HBSH-1-11 (uncorrected ${ }^{87} \mathrm{Sr} /{ }^{86} \mathrm{Sr}=0.70932 \pm 0.00004$, REE and Ca argide and dimer corrected ${ }^{87} \mathrm{Sr} /{ }^{86} \mathrm{Sr}=0.70916 \pm 0.00004$, each $2 \sigma, \mathrm{n}=3$ ) and $\mathrm{HBSH}-1-9$ (uncorrected ${ }^{87} \mathrm{Sr} /{ }^{86} \mathrm{Sr}=$ $0.70944 \pm 0.00003$, REE and Ca argide dimer corrected ${ }^{87} \mathrm{Sr} /{ }^{86} \mathrm{Sr}=0.70932 \pm 0.00003$, each $2 \sigma, \mathrm{n}=3$ ). The significant effect of the REE correction might be related to the age of the sample, which dates back to MIS 7 [58]. Thus, an old sample with high REE content needs to be properly corrected and cannot be simply considered as modern calcium carbonate specimens. Please note that all speleothem ${ }^{87} \mathrm{Sr} /{ }^{86} \mathrm{Sr}$ ratios have been corrected by standard bracketing after data evaluation with the SrDR spreadsheet, using JCt-1 as reference material to a ${ }^{87} \mathrm{Sr} /{ }^{86} \mathrm{Sr}$ ratio of $0.70917 \pm 0.00001[52]$.

\subsection{Magmatic plagioclase}

Fifteen plagioclases from a gabbroic dyke sampled in the Finero Phlogopite-Peridotite mantle unit (western Alps, Italy) were analyzed in-situ through LA-MC-ICP-MS at the CIGS laboratories (see section 5.1). Analytical parameters are identical to the fossil tooth analysis in section 5.1, with the exception that different plagioclase grains were analyzed each with one line.

Plagioclase contains ca. $3100 \mathrm{ug} / \mathrm{g}$ of Sr, only $0.6 \mathrm{ug} / \mathrm{g}$ of Rb and $19 \mathrm{ug} / \mathrm{g}$ of $\Sigma \mathrm{REE}$. The sample was previously analyzed at the Marine Environmental Sciences Laboratory (LEMAR) of the Institut Universitaire Européen de la Mer (IUEM), Université de Bretagne Occidentale (Brest, France) after conventional dissolution and chromatographic separation using a TRITON Thermal-Ionization Mass Spectrometer (TIMS) as described in [60]. TIMS analysis yielded an ${ }^{87} \mathrm{Sr} /{ }^{86} \mathrm{Sr}$ ratio of $0.704519 \pm 0.000008$ (2SE).

REE correction did not affect the ${ }^{87} \mathrm{Sr} /{ }^{86} \mathrm{Sr}$ ratio of in-situ LA-MC-ICP-MS $\mathrm{Sr}$ isotope analyses, being the uncorrected and corrected values equal within the error. The average uncorrected ${ }^{87} \mathrm{Sr} /{ }^{86} \mathrm{Sr}$ ratio is $0.704514 \pm$ $0.000057(n=15 ; 2 \sigma)$, identical to the 'true' value obtained by TIMS. 


\section{Conclusion}

Given the rapid spread of in-situ LA-MC-ICP-MS Sr isotope analyses to several fields of the applied sciences (from paleoclimate to anthropology to forensic science), we present here a fast and accurate data reduction protocol exploiting the flexibility offered by Microsoft Excel. As exemplified by our case studies, several parameters need to be considered during LA-MC-ICP-MS Sr isotope analysis and data reduction, with some differences depending on the diverse matrices that can be used to measure Sr isotopes. The SrDR spreadsheet provides a user friendly and unique way to interactively evaluate the LA-MC-ICP-MS Sr isotope data for any kind of specimen, offering different solutions based on the preferred analytical protocol and considering various possible corrections (as REE and Ca dimers/argides).

\section{Conflicts of interest}

There are no conflicts to declare.

\section{Acknowledgements}

This project was funded by the European Research Council (ERC) under the European Union's Horizon 2020 Research and Innovation Programme (grant agreement No 724046 - SUCCESS awarded to Prof. Stefano Benazzi - erc-success.eu) and by MIUR PRIN 2017 project Prot. No. 20178 LPCPW_007 (to A.C.). The Radiogenic Isotope Laboratory of the University of Modena and Reggio Emilia has been funded through a grant of the 'Programma Giovani Ricercatori Rita Levi Montalcini' (to A. C.). M. W. is thankful to the Max Planck Graduate Center with the Johannes Gutenberg University Mainz (MPGC) for funding. We also thank D. Scholz for providing speleothem sample HBSH-1 and to $\mathrm{C}$. Peretto for providing the rhinoceros tooth sample. 


\section{Data availability}

All data generated or analysed during this study are included in this paper (and its Electronic Supplementary Information files).

\section{References}

1. Faure G, Powell JL. Strontium isotope geology (Vol. 5). Springer Science \& Business Media; 2012.

2. Ericson J. Strontium isotope characterization in the study of prehistoric human ecology. J Hum Evol $1985 ; 14: 503-514$.

3. Grupe G, Price TD, Schröter P, Söllner F, Johnson CM, Beard BL. Mobility of Bell Beaker people revealed by strontium isotope ratios of tooth and bone: A study of southern Bavarian skeletal remains. Appl Geochemistry. 1997; 12:517-525.

4. Kennedy BP, Klaue A, Blum JD, Folt CL, Nislow KH. Reconstructing the lives of fish using Sr isotopes in otoliths. Can J Fish Aquat Sci. 2002; 59:925-929.

5. Price TD, Burton JH, Bentley RA. The characterization of biologically available strontium isotope ratios for the study of prehistoric migration. Archaeometry. 2002; 44:117-135.

6. Freestone IC, Leslie KA, Thirlwall M, Gorin-Rosen Y. Strontium isotopes in the investigation of early glass production: Byzantine and early islamic glass from the near East. Archaeometry. 2003; 45:19-32.

7. Barnett-Johnson R, Ramos FC, Grimes CB, MacFarlane RB. Validation of Sr isotopes in otoliths by laser ablation multicollector inductively coupled plasma mass spectrometry (LA-MC-ICPMS): opening avenues in fisheries science applications. Can J Fish Aquat Sci. 2005; 62:2425-2430. 
8. McCulloch M, Cappo M, Aumend J, Müller W. Tracing the life history of individual barramundi using laser ablation MC-ICP-MS Sr-isotopic and Sr/Ba ratios in otoliths. Mar Freshwater Res. 2005; 56: 637644.

9. Bentley RA. Strontium isotopes from the earth to the archaeological skeleton: A review. J Archaeol Method Theory. 2006; 13:135-187.

10. Lugli F. Accurate Sr isotope determination of human bone and tooth samples by LA-MC-ICP-MS: A comment on "Meijer et al.,(2019)". Int J Osteoarchaeol. 2019; 29:1109-1110.

11. Horstwood MSA, Evans JA, Montgomery J. Determination of Sr isotopes in calcium phosphates using laser ablation inductively coupled plasma mass spectrometry and their application to archaeological tooth enamel. Geochim Cosmochim Acta. 2008; 72:5659-5674.

12. Pellegrini M, Donahue RE, Chenery C, Evans J, Lee-Thorp J, Montgomery J, Mussi M. Faunal migration in late-glacial central Italy: implications for human resource exploitation. Rapid Comm Mass Spectrom. 2008; 22:1714-1726.

13. Richards M, Harvati K, Grimes V, Smith C, Smith T, Hublin JJ, et al. Strontium isotope evidence of Neanderthal mobility at the site of Lakonis, Greece using laser-ablation PIMMS. J Archaeol Sci. 2008; 35:1251-1256.

14. Degryse P, Shortland A, De Muynck D, Van Heghe L, Scott R, Neyt B, Vanhaecke F. Considerations on the provenance determination of plant ash glasses using strontium isotopes. J Archaeol Sci. 2010; 37:3129-3135.

15. Montgomery J, Evans JA, Horstwood MSA. Evidence for long-term averaging of strontium in bovine enamel using TIMS and LA-MC-ICP-MS strontium isotope intra-molar profiles. Environ Archaeol. 2010; 15:32-42.

16. Voerkelius S, Lorenz GD, Rummel S, Quétel CR, Heiss G, Baxter M, et al. Strontium isotopic signatures of natural mineral waters, the reference to a simple geological map and its potential for authentication of food. Food Chem. 2010; 118:933-940. 
17. Britton K., Grimes V, Niven L, Steele TE, McPherron S, Soressi M, et al. Strontium isotope evidence for migration in late Pleistocene Rangifer: Implications for Neanderthal hunting strategies at the Middle Palaeolithic site of Jonzac, France. J Hum Evol. 2011; 61:176-185.

18. Copeland SR, Sponheimer M, de Ruiter DJ, Lee-Thorp JA, Codron D, le Roux PJ, et al. Strontium isotope evidence for landscape use by early hominins. Nature. 2011; 474: 76-78.

19. Balter V, Braga J, Télouk P, Thackeray JF. Evidence for dietary change but not landscape use in South African early hominins. Nature. 2012; 489:558-560.

20. Bentley RA, Bickle P, Fibiger L, Nowell GM, Dale CW, Hedges REM et al. Community differentiation and kinship among Europe's first farmers. Proc Natl Acad Sci U S A. 2012; 109:9326-9330.

21. Font L, van der Peijl G, van Wetten I, Vroon P, van der Wagt B, Davies G. Strontium and lead isotope ratios in human hair: investigating a potential tool for determining recent human geographical movements. J Anal At Spectrom 2010; 27:719-732.

22. Tipple BJ, Chau T, Chesson LA, Fernandez DP, Ehleringer JR. Isolation of strontium pools and isotope ratios in modern human hair. Anal Chim Acta. 2013; 798:64-73.

23. Hartman G, Richards M. Mapping and defining sources of variability in bioavailable strontium isotope ratios in the Eastern Mediterranean. Geochim Cosmochim Acta. 2014; 126:250-264.

24. Frei KM, Mannering U, Kristiansen K, Allentoft ME, Wilson AS, Skals I, et al. Tracing the dynamic life story of a Bronze Age Female. Sci Rep. 2015; 5:10431.

25. Vautour G, Poirier A, Widory D. Tracking mobility using human hair: What can we learn from lead and strontium isotopes? Sci Justice. 2015; 55:63-71.

26. Giovanardi T, Girardi VAV, Correia CT, Sinigoi S, Tassinari CCG, Mazzucchelli M. The growth and contamination mechanism of the Cana Brava layered mafic-ultramafic complex: new field and geochemical evidences. Miner Petrol. 2017; 111:291-314. 
27. Giovanardi T, Mazzucchelli M, Lugli F, Girardi VA, Correia CT, Tassinari CC, Cipriani A. Isotopic constraints on contamination processes in the Tonian Goiás Stratiform Complex. Lithos. 2018; 310:136152.

28. Lugli F, Cipriani A, Peretto C, Mazzucchelli M, Brunelli D. In situ high spatial resolution $87 \mathrm{Sr} / 86 \mathrm{Sr}$ ratio determination of two Middle Pleistocene (c.a. 580 ka) Stephanorhinus hundsheimensis teeth by LAMC-ICP-MS. Int J Mass Spectrom. 2017; 412:38-48.

29. Lugli, F., Cipriani, A., Capecchi, G., Ricci, S., Boschin, F., Boscato, P., ... \& Richards, M. P. (2019). Strontium and stable isotope evidence of human mobility strategies across the Last Glacial Maximum in southern Italy. Nature Ecology and Evolution, 3(6), 905-911.

30. Lugli F, Cipriani A, Tavaglione V, Traversari M, Benazzi S. Transhumance pastoralism of Roccapelago (Modena, Italy) early-modern individuals: Inferences from Sr isotopes of hair strands. Am J Phys Anth. $2018 ; 167: 470-483$.

31. Sorrentino, R., Bortolini, E., Lugli, F., Mancuso, G., Buti, L., Oxilia, G., et al. Unravelling biocultural population structure in 4th/3rd century BC Monterenzio Vecchio (Bologna, Italy) through a comparative analysis of strontium isotopes, non-metric dental evidence, and funerary practices. PLOS ONE. 2018; 13: e0193796.

32. Weber M, Scholz D, Schröder-Ritzrau A, Deininger M, Spötl C, Lugli F, et al. Evidence of warm and humid interstadials in central Europe during early MIS 3 revealed by a multi-proxy speleothem record. Quat Sci Rev. 2018; 200:276-286.

33. Banner JL, Musgrove ML, Asmerom Y, Edwards RL, Hoff JA. High-resolution temporal record of Holocene ground-water chemistry: tracing links between climate and hydrology. Geology. 1996; 24:1049-1053.

34. Tütken T, Vennemann TW, Pfretzschner HU. Nd and Sr isotope compositions in modern and fossil bones-Proxies for vertebrate provenance and taphonomy. Geochim Cosmochim Acta. 2011; 75:59515970. 
35. Rittner M, Müller W. 2D mapping of LA-ICPMS trace element distributions using R. Computers \& geosciences. 2012; 42:152-161.

36. Sforna MC, Lugli F. MapIT!: a simple and user-friendly MATLAB script to elaborate elemental distribution images from LA-ICP-MS data. J Anal Atom Spectrom. 2017; 32:1035-1043.

37. Giovanardi T, Lugli F. The Hf-INATOR: A free data reduction spreadsheet for Lu/Hf isotope analysis. Earth Sci Inform. 2017; 10:517-523.

38. Giovanardi T, Freddo I, Mazzucchelli M. Filling the Gap in the Classification of Phlogopite-Bearing Ultramafic Rocks. The Journal of Geology. 2018; 12:361-370.

39. Weber M, Wassenburg JA, Jochum KP, Breitenbach SF, Oster J, Scholz D. Sr-isotope analysis of speleothems by LA-MC-ICP-MS: High temporal resolution and fast data acquisition. Chem Geol. 2017; 468:63-74.

40. Willmes M, Glessner JJ, Carleton SA, Gerrity PC, Hobbs JA. 87Sr/86Sr isotope ratio analysis by laser ablation MC-ICP-MS in scales, spines, and fin rays as a nonlethal alternative to otoliths for reconstructing fish life history. Can J Fish Aquat Sci. 2016; 73:1852-1860.

41. Kimura JI, Takahashi T, Chang Q. A new analytical bias correction for in situ Sr isotope analysis of plagioclase crystals using laser-ablation multiple-collector inductively coupled plasma mass spectrometry. J Anal Atom Spectrom. 2013; 28:945-957.

42. Paton C, Hellstrom J, Paul B, Woodhead J, Hergt J. Iolite: Freeware for the visualisation and processing of mass spectrometric data. J Anal Atom Spectrom. 2001; 26:2508-2518.

43. Zhang L, Ren ZY, Xia XP, Li J, Zhang ZF. IsotopeMaker: A Matlab program for isotopic data reduction. Int J Mass Spectrom. 2015; 392:118-124.

44. Lin J, Liu Y, Yang Y, Hu Z. Calibration and correction of LA-ICP-MS and LA-MC-ICP-MS analyses for element contents and isotopic ratios. Solid Earth Sciences. 2016; 1:5-27. 
45. Willmes M, Ransom KM, Lewis LS, Denney CT, Glessner JJ, Hobbs JA. IsoFishR: An application for reproducible data reduction and analysis of strontium isotope ratios $(87 \mathrm{Sr} / 86 \mathrm{Sr}$ ) obtained via laserablation MC-ICP-MS. PLOS ONE. 2018; 13:e0204519.

46. Vroon PZ, Van Der Wagt B, Koornneef JM, Davies GR. Problems in obtaining precise and accurate Sr isotope analysis from geological materials using laser ablation MC-ICPMS. Anal Bioanal Chem. 2008; 390:465-476.

47. Copeland SR, Sponheimer M, Lee-Thorp JA, le Roux PJ, de Ruiter DJ, Richards MP. Strontium isotope ratios in fossil teeth from South Africa: assessing laser ablation MC-ICP-MS analysis and the extent of diagenesis. J Archaeol Sci. 2010; 37:1437-1446.

48. Woodhead J, Swearer S, Hergt J, Maas R. In situ Sr-isotope analysis of carbonates by LA-MC-ICP-MS: interference corrections, high spatial resolution and an example from otolith studies. J Anal Atom Spectrom. 2005; 20:22-27.

49. Ramos FC, Wolff JA, Tollstrup DL. Measuring $87 \mathrm{Sr} / 86 \mathrm{Sr}$ variations in minerals and groundmass from basalts using LA-MC-ICPMS. Chem Geol. 2004; 211:135-158.

50. Jackson MG, Hart SR. Strontium isotopes in melt inclusions from Samoan basalts: implications for heterogeneity in the Samoan plume. Earth Planet Sci Lett. 2006; 245:260-277.

51. Glykou A, Eriksson G, Storå J, Schmitt M, Kooijman E, Lidén K. Intra-and inter-tooth variation in strontium isotope ratios from prehistoric seals by laser ablation multi-collector inductively coupled plasma mass spectrometry. Rapid Comm Mass Spectrom. 2018; 32:1215-1224.

52. Weber M, Lugli F, Jochum KP, Cipriani A, Scholz D. Calcium carbonate and phosphate reference materials for monitoring bulk and microanalytical determination of Sr isotopes. Geostand Geoanal Res. 2018; 42:77-89.

53. Berglund M, Wieser ME. Isotopic compositions of the elements 2009 (IUPAC Technical Report). Pure Appl Chem. 2011; 83:397-410. 
54. Simonetti A, Buzon MR, Creaser RA. In-situ elemental and Sr isotope investigation of human tooth enamel by laser ablation-(MC)-ICP-MS: Successes and pitfalls. Archaeometry. 2008; 50:371-385.

55. Irrgeher J, Galler P, Prohaska T. $87 \mathrm{Sr} / 86 \mathrm{Sr}$ isotope ratio measurements by laser ablation multicollector inductively coupled plasma mass spectrometry: Reconsidering matrix interferences in bioapatites and biogenic carbonates. Spectrochim Acta Part B At Spectrosc. 2016; 125:31-42.

56. Willmes M, Kinsley L, Moncel MH, Armstrong RA, Aubert M, Eggins S, Grün R. Improvement of laser ablation in situ micro-analysis to identify diagenetic alteration and measure strontium isotope ratios in fossil human teeth. J Archaeol Sci. 2016;70:102-116.

57. McArthur JM, Howarth RJ, Bailey TR. Strontium isotope stratigraphy: LOWESS version 3: best fit to the marine Sr-isotope curve for 0-509 Ma and accompanying look-up table for deriving numerical age. The Journal of Geology. 2001; 109:155-170.

58. Scholz D, Hoffmann DL, Spötl C, Hopcroft P, Mangini A, Richter DK. Decoupled evolution of temperature and precipitation in Western Germany during the Last Interglacial reconstructed from a precisely dated speleothem. Mineralogical Magazine. 2011; 75:1823.

59. Lin Y, Jochum KP, Scholz D, Hoffmann DL, Stoll B, Weis U, Andreae MO. In-situ high spatial resolution LA-MC-ICPMS 230Th/U dating enables detection of small-scale age inversions in speleothems. Solid Earth Sciences. 2017; 2:1-9.

60. Giovanardi T, Zanetti A, Dallai L, Morishita T, Hémond C, Mazzucchelli M. Evidence of subductionrelated components in sapphirine-bearing gabbroic dykes (Finero phlogopite-peridotite): Insights into the source of the Triassic-Jurassic magmatism at the Europe-Africa boundary. Lithos. 2020; https://doi.org/10.1016/j.lithos.2020.105366. 
Figure 1. (a) Overview of the SrDR spreadsheet workflow; (b) data reduction philosophy, including the proposed corrections.

Figure 2. Analyses of a Middle Pleistocene rhinoceros tooth. (a) Signal (V) of $\mathrm{m} / \mathrm{z} 86.5\left({ }^{173} \mathrm{Yb}^{++}\right)$is correlated with signal of $\mathrm{m} / \mathrm{z} 82$. (b) Signals of $\mathrm{m} / \mathrm{z} 82$ and 83 are strongly correlated. (c) The increase of the $\mathrm{m} / \mathrm{z} 82$ signal during the ablation of the fossil tooth (and not during the ablation of the modern swine tooth) suggests its correlation with the presence of REEs within the sample, in particular with ${ }^{164} \mathrm{Dy}^{++}$. (d) The REE-uncorrected ${ }^{87} \mathrm{Sr} /{ }^{86} \mathrm{Sr}$ ratio and the REE-corrected ${ }^{87} \mathrm{Sr} /{ }^{86} \mathrm{Sr}$ ratio are significantly different (see text for details). Error bars are 2 se. The small red square over the tooth photograph represents the area where the analyses were performed (both solution and LA).

Figure $3 .{ }^{87} \mathrm{Sr} /{ }^{86} \mathrm{Sr}$ and ${ }^{84} \mathrm{Sr} /{ }^{86} \mathrm{Sr}$ data of RHIS14 (Middle Pleistocene rhinoceros tooth) after each single correction step using Sr-DR sheet. The blue line is the reference ${ }^{84} \mathrm{Sr} /{ }^{86} \mathrm{Sr}$ value $(0.0565)$; while the red line is ${ }^{87} \mathrm{Sr} /{ }^{86} \mathrm{Sr}$ ratio of the tooth enamel $(0.70954)$ obtained by solution MC-ICP-MS.

Figure 4. ${ }^{87} \mathrm{Sr} /{ }^{86} \mathrm{Sr}$ and ${ }^{84} \mathrm{Sr} /{ }^{86} \mathrm{Sr}$ of a modern seashell. As example, analysis \#6 reveals a slightly deviated ${ }^{84} \mathrm{Sr} /{ }^{86} \mathrm{Sr}$ ratio (0.05637), even if the ${ }^{87} \mathrm{Sr} /{ }^{86} \mathrm{Sr}$ perfectly match the modern seawater (0.70918). Error bars are $2 \mathrm{se.}$

Figure 5. Stalagmite sample from the Hüttenbläserschachthöhle (Germany). In-situ Sr isotope analyses (red squares) were performed using a Nu plasma mass spectrometer and a $213 \mathrm{~nm}$ laser ablation system. Numbers $(20,11,9)$ represent the slab ID (HBSH-1-20, HBSH1-9 and HBSH-1-11). See text for details. 
Table 1: Sr isotopes and possible sources of interference.

\begin{tabular}{|c|c|c|c|c|c|c|c|c|c|c|c|}
\hline$m / z$ & 88 & 87 & 86.5 & 86 & 85.5 & 85 & 84 & 83.5 & 83 & 82 & 81.5 \\
\hline Strontium & ${ }^{88} \mathrm{Sr}$ & ${ }^{87} \mathrm{Sr}$ & - & ${ }^{86} \mathrm{Sr}$ & - & - & ${ }^{84} \mathrm{Sr}$ & - & - & - & - \\
\hline Interferences & $\begin{array}{l}{ }^{176} \mathrm{Yb} \\
{ }^{176} \mathrm{Lu} \\
{ }^{176} \mathrm{Hf} \\
{ }^{40} \mathrm{Ca}{ }^{48} \mathrm{Ca} \\
{ }^{40} \mathrm{Ar}{ }^{48} \mathrm{Ca}\end{array}$ & $\begin{array}{c}{ }^{87} \mathrm{Rb} \\
{ }^{174} \mathrm{Yb} \\
{ }^{43} \mathrm{Ca}^{44} \mathrm{Ca} \\
{ }^{40} \mathrm{Ca}^{31} \mathrm{P}^{16} \mathrm{O} \\
{ }^{40} \mathrm{Ar}^{31} \mathrm{P}^{16} \mathrm{O}\end{array}$ & ${ }^{173} Y b$ & $\begin{array}{c}{ }^{86} \mathrm{Kr} \\
{ }^{172} \mathrm{Yb} \\
{ }^{40} \mathrm{Ca}{ }^{46} \mathrm{Ca} \\
{ }^{42} \mathrm{Ca}^{44} \mathrm{Ca} \\
{ }^{40} \mathrm{Ar}{ }^{46} \mathrm{Ca}\end{array}$ & ${ }^{171} Y b$ & $\begin{array}{l}{ }^{85} \mathrm{Rb} \\
{ }^{170} \mathrm{Yb} \\
{ }^{170} \mathrm{Er} \\
{ }^{42} \mathrm{Ca}^{43} \mathrm{Ca}\end{array}$ & $\begin{array}{c}{ }^{84} \mathrm{Kr} \\
{ }^{168} \mathrm{Yb} \\
{ }^{168} \mathrm{Er} \\
{ }^{40} \mathrm{Ca}^{44} \mathrm{Ca} \\
{ }^{40} \mathrm{Ar}{ }^{44} \mathrm{Ca}\end{array}$ & ${ }^{167} \mathrm{Er}$ & $\begin{array}{c}{ }^{83} \mathrm{Kr} \\
{ }^{166} \mathrm{Er} \\
{ }^{40} \mathrm{Ca}{ }^{43} \mathrm{Ca} \\
{ }^{40} \mathrm{Ar}{ }^{43} \mathrm{Ca}\end{array}$ & $\begin{array}{l}{ }^{164} \mathrm{Er} \\
{ }^{164} \mathrm{Dy} \\
{ }^{40} \mathrm{Ca}^{42} \mathrm{Ca} \\
{ }^{40} \mathrm{Ar} \mathrm{r}^{42} \mathrm{Ca}\end{array}$ & ${ }^{163} D y$ \\
\hline
\end{tabular}




\begin{tabular}{|c|c|c|c|c|c|c|c|c|c|c|c|c|c|c|c|}
\hline \multicolumn{16}{|c|}{$\begin{array}{l}\text { Table 2. Different spreadsheet versions, based on the } \\
\text { analytical protocol employed for the analysis. }\end{array}$} \\
\hline & $m / z$ & 82 & 83 & 83.5 & 84 & 85 & 85.5 & 86 & 86.5 & 87 & 88 & $\begin{array}{l}189 \\
)^{*}\end{array}$ & & & \\
\hline & \begin{tabular}{|l|} 
Isotop \\
e
\end{tabular} & $\begin{array}{l}82 \\
\mathrm{Kr}\end{array}$ & $\begin{array}{l}83 \\
\mathrm{Kr}\end{array}$ & $\begin{array}{l}\begin{array}{l}167 \\
+ \\
++\end{array} \\
+\end{array}$ & $\begin{array}{l}84 \\
\mathrm{Sr}\end{array}$ & ${ }_{b}^{85} R$ & $\begin{array}{ll}{ }_{171}^{171} \\
++\end{array}$ & $\begin{array}{l}86 \\
\mathrm{Sr}\end{array}$ & $\begin{array}{l}{ }^{173} Y \mathrm{~b} \\
++\end{array}$ & ${ }^{87} \mathrm{Sr}$ & ${ }^{88} \mathrm{Sr}$ & ${ }^{89} \mathrm{Y}$ & $\begin{array}{l}\text { Correcti } \\
\text { ons }\end{array}$ & Notes & $\begin{array}{l}\text { Literature } \\
\text { examples }\end{array}$ \\
\hline \multirow{5}{*}{ 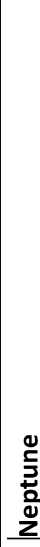 } & V1 & $x$ & $x$ & & $x$ & $x$ & & $x$ & & $x$ & $x$ & $x$ & $\begin{array}{l}\mathrm{ArCa}+\mathrm{Ca} \\
\mathrm{Ca}\end{array}$ & $\begin{array}{l}\text { Best option for modern samples } \\
\text { containing no REE. ArCa and Caca } \\
\text { correction assumes no REE content. }\end{array}$ & {$[13]+{ }^{89} \mathrm{Y}$} \\
\hline & V2 & $x$ & $x$ & $x$ & $x$ & $x$ & & $x$ & $x$ & $x$ & $x$ & & $\begin{array}{l}\mathrm{REE} \text { and } \\
\mathrm{ArCa}+\mathrm{Ca} \\
\mathrm{Ca}\end{array}$ & $\begin{array}{l}\text { Best option for fossil samples } \\
\text { containing high REE. }\end{array}$ & {$[8]+{ }^{82} \mathrm{Kr}$} \\
\hline & V3 & $x$ & $x$ & & $x$ & $x$ & $x$ & $x$ & $x$ & $x$ & $x$ & & REE & $\begin{array}{l}\text { Alternative option for both fossil and } \\
\text { modern samples. Not possible to } \\
\text { properly check for ArCa and CaCa. Er } \\
\text { corrected using } \mathrm{m} / \mathrm{z} 83 \text {. }\end{array}$ & [28] \\
\hline & V4 & $x$ & $x$ & & $x$ & $x$ & & $x$ & $x$ & $x$ & $x$ & & REE & $\begin{array}{l}\text { Alternative option for both fossil and } \\
\text { modern samples. Not possible to } \\
\text { properly check for ArCa and CaCa. }\end{array}$ & [47] with $\mathrm{Nu}$ \\
\hline & V5 & & $x$ & $x$ & $x$ & $x$ & $x$ & $x$ & $x$ & $x$ & $x$ & & REE & $\begin{array}{l}\text { Alternative option for both fossil and } \\
\text { modern samples. }\end{array}$ & [49] \\
\hline \multirow[b]{3}{*}{$\begin{array}{l}\frac{\pi}{5} \\
\frac{5}{0} \\
\frac{\pi}{2} \\
z \\
z\end{array}$} & V1 & $x$ & $x$ & & $x$ & $x$ & & $x$ & & $x$ & $x$ & $x$ & $\begin{array}{l}\mathrm{ArCa}+\mathrm{Ca} \\
\mathrm{Ca}\end{array}$ & \begin{tabular}{|l|} 
Best option for modern samples \\
containing no REE. ArCa and CaCa \\
correction assumes no REE content.
\end{tabular} & {$[45]+{ }^{89} \mathrm{Y}$} \\
\hline & \begin{tabular}{|l|} 
V2 \\
\end{tabular} & $x$ & $x$ & & $x$ & $x$ & & $x$ & & $x$ & $x$ & & $\begin{array}{l}\mathrm{ArCa}+\mathrm{Ca} \\
\mathrm{Ca}\end{array}$ & $\begin{array}{l}\text { Best option for modern samples } \\
\text { containing no REE. ArCa and } \mathrm{CaCa} \\
\text { correction assumes no REE content. }\end{array}$ & [45] \\
\hline & V3 & $x$ & $x$ & $x$ & $x$ & $x$ & $x$ & $x$ & $x$ & $x$ & $x$ & & $\begin{array}{l}\text { REE and } \\
\mathrm{ArCa}+\mathrm{Ca} \\
\mathrm{Ca}\end{array}$ & $\begin{array}{l}\text { Best option for fossil samples } \\
\text { containing high REE. }\end{array}$ & [39] \\
\hline
\end{tabular}


a.

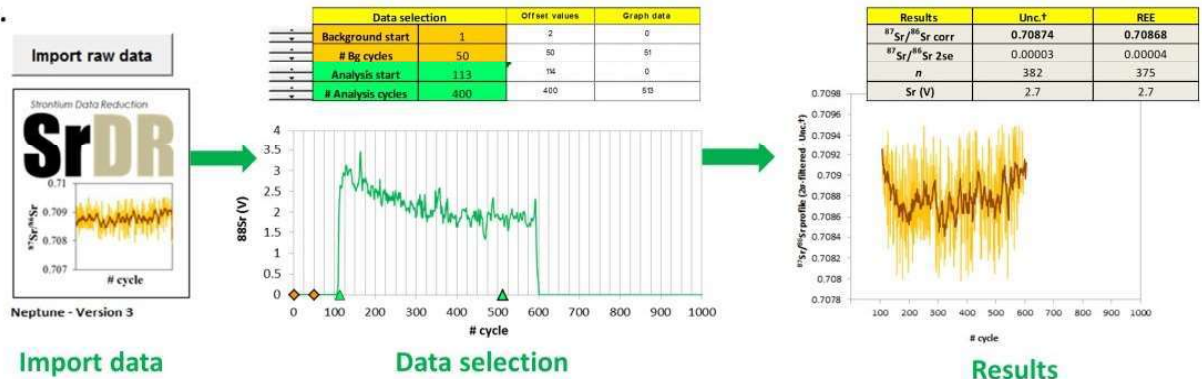

b.

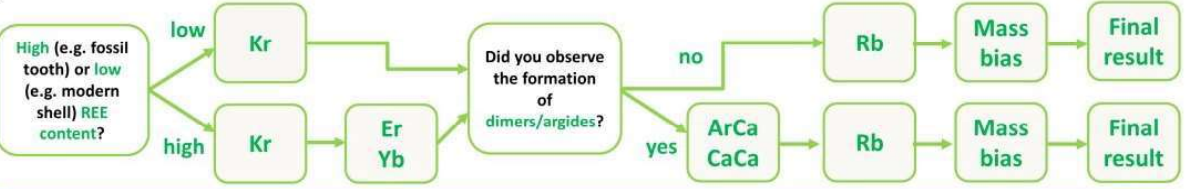

Once you obtained the final result: is your sample a (bio)apatite? Please consider the possible interference of Ar-CaPO on $m / 287$ (not corrected by the SrDR spreadsheet).

Figure 1. (a) Overview of the SrDR spreadsheet workflow; (b) data reduction philosophy, including the proposed corrections.

$349 \times 209 \mathrm{~mm}(223 \times 223 \mathrm{DPI})$ 

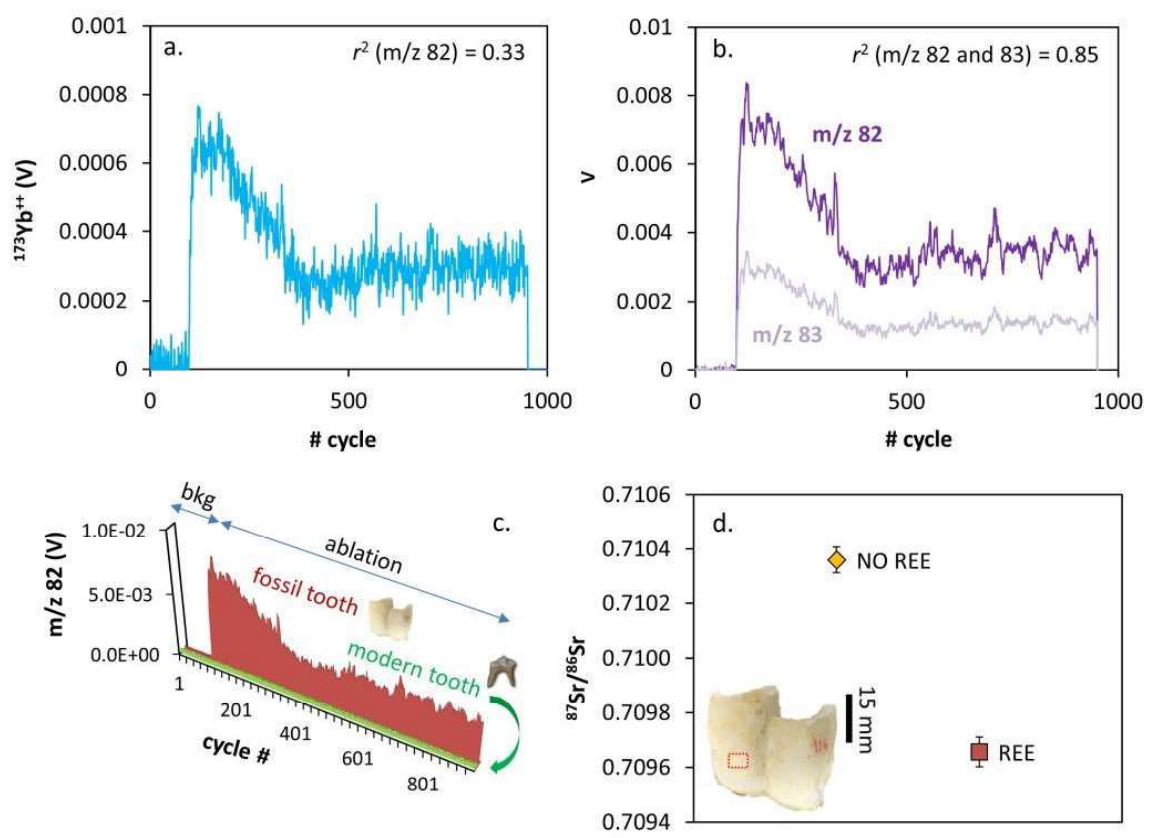

Figure 2. Analyses of a Middle Pleistocene rhinoceros tooth. (a) Signal (V) of $\mathrm{m} / \mathrm{z} 86.5(173 \mathrm{Yb}++$ ) is correlated with signal of $\mathrm{m} / \mathrm{z}$ 82. (b) Signals of $\mathrm{m} / \mathrm{z} 82$ and 83 are strongly correlated. (c) The increase of the $\mathrm{m} / \mathrm{z} 82$ signal during the ablation of the fossil tooth (and not during the ablation of the modern swine tooth) suggests its correlation with the presence of REEs within the sample, in particular with 164Dy++. (d) The REE-uncorrected $87 \mathrm{Sr} / 86 \mathrm{Sr}$ ratio and the REE-corrected $87 \mathrm{Sr} / 86 \mathrm{Sr}$ ratio are significantly different (see text for details). Error bars are $2 \mathrm{se}$. The small red square over the tooth photograph represents the area where the analyses were performed (both solution and LA). 


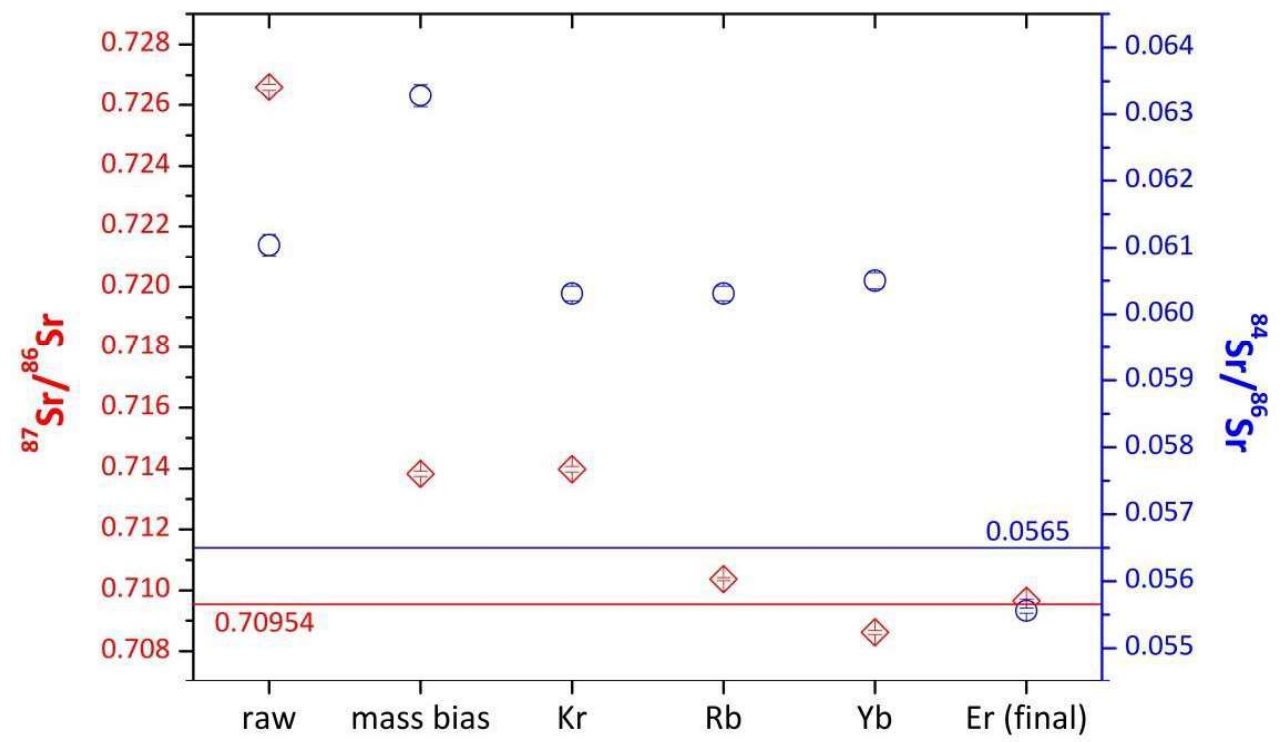

Corrections

Figure 3. $87 \mathrm{Sr} / 86 \mathrm{Sr}$ and $84 \mathrm{Sr} / 86 \mathrm{Sr}$ data of RHIS14 (Middle Pleistocene rhinoceros tooth) after each single correction step using Sr-DR sheet. The blue line is the reference $84 \mathrm{Sr} / 86 \mathrm{Sr}$ value $(0.0565)$; while the red line is $87 \mathrm{Sr} / 86 \mathrm{Sr}$ ratio of the tooth enamel $(0.70954)$ obtained by solution MC-ICP-MS. 

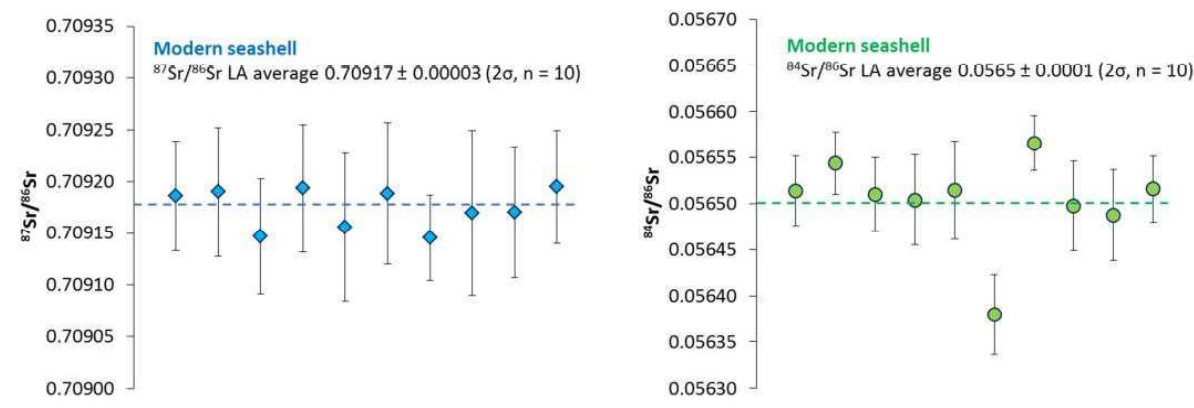

Figure $4.87 \mathrm{Sr} / 86 \mathrm{Sr}$ and $84 \mathrm{Sr} / 86 \mathrm{Sr}$ of a modern seashell. As example, analysis \# 6 reveals a slightly deviated $84 \mathrm{Sr} / 86 \mathrm{Sr}$ ratio $(0.05637)$, even if the $87 \mathrm{Sr} / 86 \mathrm{Sr}$ perfectly match the modern seawater $(0.70918)$. Error bars are $2 \mathrm{se}$.

$254 \times 90 \mathrm{~mm}(300 \times 300 \mathrm{DPI})$ 

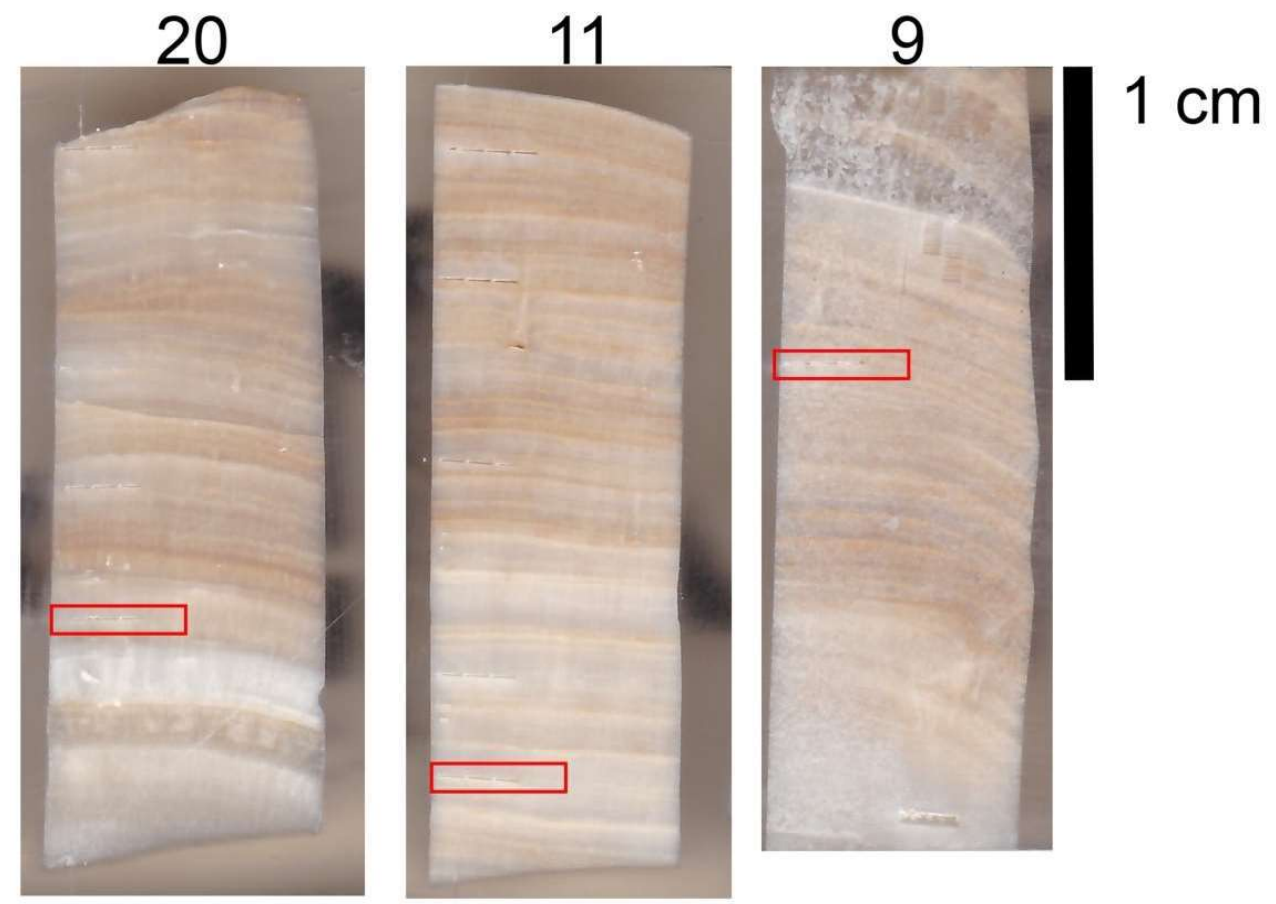

Figure 5. Stalagmite sample from the Hüttenbläserschachthöhle (Germany). In-situ Sr isotope analyses (red squares) were performed using a Nu plasma mass spectrometer and a $213 \mathrm{~nm}$ laser ablation system. Numbers $(20,11,9)$ represent the slab ID (HBSH-1-20, HBSH-1-9 and HBSH-1-11). See text for details. 